\title{
DISCURSO CELEBRACION DE 10 AÑOS DE REFORMA PROCESAL PENAL 2000-2010. Corte de Apelaciones Temuco
}

16 de diciembre de 2010.

Álvaro Mesa Latorre ${ }^{1}$

Hablar de sistemas penales, de sistema procesales penales- hay que decirlo siempre con toda la fuerza- es recordar que para el hombre, en los últimos 2 mil años de historia ha significado asfixia, aniquilamiento, muerte, equivocación tras equivocación, limitación absoluta de su libertad. De lo que trata la inflexión actual, es buscar un equilibrio que permita a la comunidad, respetando la plenitud de derechos, restaurar, integrar, recuperar, florecer, dar luz donde se ha ceñido la sombra. La ultima ratio no es la aplicación de una medida extrema, ni la condena, el último fundamento. Lo único que nos queda como racionalidad es diseñar un sistema penal y un sistema procesal penal, pues aquello, es indiciario que por múltiples factores como grupo humano, habiendo podido escoger otra convivencia más enaltecedora del espíritu humano, no pudimos hacerlo. Por ello construir hoy un Sistema Procesal Penal (SPP), es arriesgarnos a coartar al hombre, pero también es reunir en un mismo lugar la mejor tradición jurídica para proteger la libertad. Una armonía permanente por la hay que luchar. (He ahí nuestro punto crucial.) Recordemos que en la actual Inglaterra hacia el año 1215, unos hombres lograron obtener una carta de derechos del Gobernante, que es útil recordar en el 2010: "Ningún hombre libre, será arrestado o detenido en prisión o desposeído de sus bienes, proscrito o desterrado o molestado de alguna manera y no dispondremos sobre él. No lo pondremos en prisión sino por el juicio legal de sus pares o por la ley del país. A nadie venderemos, a nadie negaremos, ni retardaremos el Derecho a la justicia. Con esa mirada -por supuestotranscurridos 10 años desde que la flecha de la sensatez clavó su cielo en la Región de La Araucanía, esto produjo un giro estructural en el paisaje societario chileno. (Estábamos perdidos.) La Reforma Procesal Penal (RPP) vino a oxigenar al derecho, a todos los habitantes del Derecho. El camino tomado entonces, debe apuntar a lo expuesto por el pensador Benjamín Constant en 1797 (post-Revolución Francesa):

1 Abogado. Licenciado en Ciencias Jurídicas y Sociales de la Universidad de Valparaíso. Diplomado en Reforma Procesal Penal Universidad de Magallanes. Chile. Académico Escuela de Derecho Universidad Mayor sede Temuco. Correo: amesa@pjud.cl 
"Desde que el espíritu del hombre emprendió su marcha no hay invasión de bárbaros, ni condición de agresores ni evocación de prejuicios que pueda hacerle retroceder". Ahora hemos emprendido el viaje, surcando miles de mundos inimaginables 30 años atrás. Así por ejemplo, la característica del discurso jurídico contemporáneo radica en abordar de un modo exclusivo sea cualquiera el tema en términos de derechos, esto es Prerrogativas, facultades o poderes de los sujetos jurídicos. El derecho nos hizo dar vuelta todo lo que aprendimos de racional y jurídico. Hay un revisitar al hombre, un repensar, un renacer. Habermas nos dirá que hay que tener cuidado de nuestros poderes, una fuerte racionalización en la acción política y social, puede transformarse en algo racional meramente instrumental, acabando en una completa irracionalidad en cuanto a los fines de la acción. Edades, décadas, todos conocimos las anteriores ciudades jurídicas, sus ríos, sus praderas y en un claro del bosque nos dimos cuenta que es el tiempo de la modernidad reflexiva (cambiar, crear, fundamentar, humanizar). Hay que dejar atrás la voluntad que nos carcome y actuar con razonabilidad. Debemos pensar, ponderar hasta que duela, hasta desmayarnos, para, al decir de Dworkin, recorrer toda historia del precedente anterior y buscar la mejor solución. En ese contexto, nada mejor (como Dante con Virgilio en la Divina Comedia) acercarse a las profundidades y a las alturas del hombre -de eso se trata un SPP- que citando a lo nuestro. Nicanor Parra ya en década 1950 nos hablaba de los vicios del mundo moderno: Las discriminaciones, los trucos de la alta banca, la catástrofe de los ancianos, el comercio clandestino de blancas. Agregaba que el mundo moderno se compone de flores artificiales, que se cultivan en una campana de vidrio parecida a la muerte. Nicanor te decimos que hay que levantar otro mundo, los vicios se han multiplicado, buscamos respuestas, y a la mano tenemos una fantasía Ilamado Derecho (que hoy la Ilamamos RPP y nos permite con mayor claridad entendernos). En esa misma línea Vicente Huidobro en su poema el Paso del Retorno expresó: "Este es aquel que llegó al final del último camino

Y que vuelve quizás con otro paso

Hago al andar el ruido de la muerte

Y si mis ojos os dicen cuanta vida he vivido y cuanta muerte he muerto

Ellos podrían también deciros

Cuánta vida he muerto y cuánta muerte he vivido.

Vicente, también te contamos que apenas hemos abierto esta primera ventana

Y quizás nuestra mirada se ha extendido levemente.

Avanzamos por las calles y anhelamos producir el ruido de la libertad".

Nuestras palabras pueden decirnos que estamos resucitando lo mejor de la vida y de la muerte.

Esta es la reforma, viene hacia nosotros con fuerza y atraviesa transformando una sociedad más respetuosa de la persona. Somos seres culturales -no biológicos, aunque sigamos siendo biológicamente Homo Sapiens- Sapiens. Al decir del biólogo Humberto Maturana la cultura son redes de conversaciones, un modo de vivir entre 
el lenguaje y el emocionar. Todo lo que aprendemos es la realización de un quehacer. Entonces si ese quehacer se hace en el respeto de los derechos, aprendemos sobre dignidad, sobre legitimidad, sobre la otredad. Todo conocimiento es un modo de vivir y por tanto multidimensional. El individuo con el que estamos conviviendo, es ese sujeto individual humano, un hombre con sus artes, con sus aparejos y múltiples perfiles.

Lo humano (la RPP es lo humano de lo humano) a diferencia de los demás seres, es conocer los extremos, la avaricia, la codicia, los prejuicios la crueldad. Pero también permite darnos cuenta de aquellos ideales que podemos alcanzar esto es ser críticos, racionales, modernos constructivos, inclusivos. Hacia allá va la RPP. Nos hemos embarcado hacia el bien y hacia el mal, y será un desafío permanente afirmar el buen camino. En estos 10 años quizás hemos rozado algo que indicó John Rawls en su Teoría de la Justicia en cuanto una sociedad bien ordenada se define como una sociedad regulada con eficiencia por una concepción pública de la justicia. Los participantes se conciben asimismo como personas libres de revisar y alterar sus objetivos finales y dar prioridad a este respecto a la conservación de la libertad.

Aspiramos a estar en una postmodernidad también constructivista. Que estos 10 pasados años nos den fortaleza y los 100 que vienen no terminemos siendo lo que narró Pablo Neruda en Walking Around.

Sucede que me canso de ser hombre

Sucede que me canso de mis pies de mis uñas

No quiero seguir siendo raíz de las Tinieblas,

Vacilante, extendido, tiritando de sueño. Habrá que decir a Pablo que la persona quiere ser más hombre, más mujer que nunca, quiere conocer la plenitud y ser raíz de la libertad.

No importan como dice Elicura Chihuailaf, que nos digan que la poesía no sirve para nada y en el bosque los árboles se acarician con sus raíces azules y agitan sus ramas al aire... Elicura (piedra transparente) también nos han dicho que el Derecho y sus teorías no sirven para nada, pero hemos visto cómo a través de él la justicia ha llegado al corazón de muchos seres.

Sí es verdad, la RPP es algo parcial, no engloba la totalidad del sistema de justicia y tiene serias y graves falencias en la etapa de cumplimiento, pero por otro lado nos ha anclado en este Territorio de la Frontera y como tal siempre estamos es un inicio y un final.

La RPP ha producido infinitos cambios y parafraseando al Pintor Roberto Matta nos muestra aquello que el ojo, la mente, el alma no alcanza a ver. 
Nos ha hecho entrar en una comunidad de valores. Este es nuestro sistema normativo, si hay otro mejor hay que tomarlo.

El hecho que estemos aquí celebrando los 10 años es un signo positivo que creemos en ella.

La RPP, dio el primer paso y abrió océanos inmensos. Fue y es pauta y modelo para otros reformas de justicia. Aprendimos a lograr consensos.

Aprendimos que pueden construirse, siempre, mejores métodos normativos Nos mostró la belleza de la audiencia pública, su rito, sus colores, su verdad.

Nos mostró otras disciplinas y otras arquitecturas.

Nos mostró una administración sin precedentes de la cual Max Weber estaría orgulloso.

Esta es el ave que quiere volar, atravesando todos los desiertos.

Nos trajo no un nuevo mundo normativo, sino toda la galaxia normativa. La solución la podemos encontrar en el universo y no solo en nuestra aldea.

Nos hicimos globales, ciudadanos jurídicos del mundo.

Pudimos vivir en profundidad la nervadura, la sangre, los huesos, la carne, el alma de lo que significan los grandes pactos internacionales de derechos humanos.

Nos acercó al Auditorio Universal y saludamos entonces con autoridad y propiedad entre tantos a Cesare Beccaría, De la Mirándola, Ficino, Giordano Bruno, Stuart Mill, Calamandrei, Carrara, Roxin, Muñoz Conde, Ragués y Valles, Binder, Mayer, Alexy, Ruiz Manero, Gascón Avellán, Bobbio, Taruffo, Cobreros Mendazona, Fioravanti, Montañez Pardo, Hassemer, Levinas, Harrington, Coke, Peces Barba, Esparza, Harris, Oboyle, Warbrick. y todos loa anónimos que nos acompañan siempre en nuestros corazones.

La RPP nos hizo ver la lucidez jurídica que existe en el cuerpo académico chileno.

Nos mostró la eficiencia y aplicación que cada institución puso para el funcionamiento del sistema.

Este es el cielo que hemos forjado, también el otro bosque.

Más amplios, profundos y transparentes que nunca. Hay que seguir abriéndolos y descubriéndolos (queda un largo recorrido que realizar). Aquí está lleno de estrellas 
y vida como la presunción de inocencia, el derecho a un juicio oral y público, la duda razonable, la publicidad, la inmediación, la audiencia preparatoria, las medidas alternativas, la fundamentación no solo de la resoluciones, sino de todo nuestro actuar, la coherencia, la proporcionalidad, la valoración libre de la prueba. Quedan muchas por descubrir. Gabriela Mistral al recibir el Premio Nobel en 1945 señaló que le gustaría que nuestra juventud pensara y expresara que los pensamientos libres son buenos, pero los justos son mejores. Hacia allá vamos Gabriela.

Gracias.

Álvaro Mesa Latorre Ministro Corte de Apelaciones de Temuco 
